\title{
Motivation and mobile devices: exploring the role of appropriation and coping strategies
}

\author{
Ann Jones* and Kim Issroff \\ The Open University, UK
}

There has been interest recently in how mobile devices may be motivating forces in the right contexts: for example, one of the themes for the IADIS International Conference on Mobile Learning in 2007 was 'Affective Factors in Learning with Mobile Devices' (http://www.mlearningconf.org). The authors have previously proposed six aspects of learning with mobile devices in informal contexts that might be motivating: control over learners' goals, ownership, fun, communication, learning-in-context and continuity between contexts. How do these motivational features relate to theoretical accounts of what motivates people to use mobile devices and learn in technology-rich contexts? In this exploratory paper we consider two different candidates for such theoretical approaches. One is technology appropriation - the process by which technology or particular technological artefacts are adopted and shaped in use. Two different approaches to technology appropriation are discussed in order to explore the relationship between the different aspects of appropriation and motivation; that of Carroll et al. and that of Waycott. Both appropriation frameworks have been developed in the context of using mobile devices, but neither has a specific focus on learning. By contrast, the second theoretical approach is Järvelä et al.'s model of coping strategies, which is specifically concerned with learning with technologies, although not with mobile technologies in particular. The paper draws on case-study data in order to illustrate and discuss the extent to which these two approaches are helpful in informing our understanding of the motivating features of using mobile devices for informal learning.

\section{Background}

Research on learning outside institutional contexts indicates a high level of informal learning in the adult population: for example, Tough's (1979) study, one of a number of case studies in the 1970 s, suggested that up to $98 \%$ of adults engage in informal learning; and much more recent figures also suggest substantial engagement in informal learning. A Canadian survey revealed that adults spend an average of 15 hours

\footnotetext{
*Corresponding author. Institute of Educational Technology, The Open University, Milton
} Keynes MK7 6AA, UK. Email: a.c.jones@open.ac.uk 
per week on informal learning projects (Livingstone, 2006). There is much discussion in the literature about the definition of informal learning and different typologies of different kinds of learning. Livingstone describes informal learning as ' ... self-directed informal learning per se is most simply understood as learning that is taken on the learner's or learners' own terms without either prescribed curricular requirements or a designated instructor' (Livingstone, 2006, p. 205). Looking at informal mobile learning, Clough et al. (in press) survey personal digital assistant (PDA) and Smartphone enthusiasts from web fora and found that 100 of her 200 respondents described informal learning with mobile devices. These experienced mobile device users found inventive and ingenious ways of using their devices to support their informal learning. In another study by Pettit and Kukulska-Hulme (2007), alumni of a Masters Programme in Online and Distance Education were surveyed about their experience of using mobile devices. These participants were also creative in the way they combined their devices to support their learning - although here it was often in a formal context.

The use of mobile devices has now become commonplace around the world, with non-western countries showing the highest rates of current growth. This is in spite of known usability issues in using portable devices (for an overview, see KukulskaHulme, 2007). Usability problems are linked to small screen size (Waycott, 2004; Corlett et al., 2006) as well as problems with entering data into the device (Smørdal \& Gregory, 2003). The extensive use of mobiles suggests that there are strong incentives for people to persist in using their mobile devices even where usability problems are experienced. This led us to consider what aspects of using mobile devices might be so motivating for informal learners.

Drawing from the literature on both mobile learning and informal learning, Jones et al. (2006) proposed six reasons why mobile informal learning might be motivating: control (over learners' goals), ownership, learning-in-context, continuity between contexts, fun and communication - the first four of these motivational factors were discussed in more detail in Issroff et al. (2007). These features are not viewed as a definitive list or set, but as a starting point for exploring the motivational pull of using mobile devices - an area that, like affective issues in learning more generally, has been rather neglected in learning research until relatively recently. In this paper we explore how these features relate to two lines of relevant theoretical work-that of appropriation, which focuses on the adoption and use of devices, and that of coping strategies in learning with technologies. Before discussing technology appropriation and coping strategies, the proposed motivational factors are outlined in a little more detail.

The first motivational factor is that in the context of informal learning, learners have control over their own goals and the freedom to define the tasks and activities they wish to engage in. The very nature of informal learning means that there is a strong relationship to learners' goals and interests, and so intrinsic motivation is likely to be high.

Second, mobile devices seem to give their users a strong sense of ownership. In the motivational literature, ownership is often highlighted as a key motivational factor but can refer to ownership of the learning or of learning products. In the context of mobile 
devices it also refers to physical ownership of the devices and their personal nature. Mobile devices are much more likely to be viewed as individual personal property than other kinds of digital tools and resources (Waycott, 2004). A study on the use of tablet PCs in schools (Twining \& Evans, 2005) suggested that ownership was also important in this more formal context.

Third, many mobile devices also allow users to communicate, thus enabling and supporting collaborative learning. Crook (2000) has suggested that working with other people, given the right conditions, is in itself motivating.

Fourth, mobile devices are widely used for entertainment, especially by young people, so it is possible that the emotion and the excitement generated by this use may be associated with the device-mobiles become identified as ' $f u n$ ' devices.

Fifth, mobile devices enable learners to access resources and information in the context where they are needed and used, including 'in the field' and to share this information with others. For example, the amateur naturalist can access web sites from their mobile device, which provide identification guides (including audio and video) to support them in identifying what they see at the point they need this information.

Finally, the portability of mobile devices can provide continuity between different settings so that information or resources that have been captured in one context can be transported to another. Learners can therefore use these devices to support their informal learning projects over time and in different locations-suiting the episodic nature of much informal learning, which is carried out in small, distributed chunks (Vavoula \& Sharples, 2002).

These features therefore suggest that using mobiles in informal settings is likely to be highly motivating, but a list of features alone is not sufficient to account for the motivational process. Mobile learning, as a new area, is generally under-theorised. Sharples et al. (2007) have recently proposed a theory of learning for the mobile age, but while this does emphasise learning as a personally managed lifelong activity there is little focus on affective issues such as motivation.

\section{Theoretical approaches: technology appropriation and coping strategies}

In this section two theoretical approaches are considered as candidates to help us understand the motivational power of mobile learning: technological appropriation, and Järvelä et al.'s (2000) model of coping strategies. Appropriation has been chosen because this has previously been used to understand why and how people choose to use mobile technologies in a range of settings, and is therefore very relevant to understanding what motivates the use of mobile devices. The Järvelä et al. model, by contrast, focuses on learning with technologies although these are fixed technologies. Can these two approaches help to extend and understand the motivational factors we have identified?

Järvelä et al.'s study was reported in 2000, the study by Carroll et al. in 2002 and Waycott's study in 2004. However, although there is a rapid change in terms of technological development, the different temporal locations of the study (or indeed the different contexts) are not problematic for our discussion about motivation. 
Indeed, many studies about technology-supported learning have shown that the same issues and principles re-occur even though the technology changes-for example, the issue about the need to have the use of technology for learning assessed and for this assessment to be integrated is one that emerged from studies in the early 1980s and is still current today (see, for example, Jones \& O'Shea, 1982; Kirkwood \& Price, 2005). Accessibility is also a recurring issue-in the 1970 s and 1980 s, when there were few personal computers, learners found it hard to get access to computers: now there is almost ubiquitous access, but there is often an expectation that learners can be online frequently, which does not fit with the life and work patterns of many learners so the issue has not gone away. The intention is not to compare the strengths of one theory against the other, or to compare the studies with each other, but to consider the benefits of each of them to see how the theoretical concepts from those studies can be applied to our data and how they help us with understanding motivation and mobile technologies.

\section{Technology appropriation}

Carroll et al. (2002) discuss the role of mobile technologies in the lives of young people and why some technologies are adopted by young people and not others. They propose a model of appropriation that they define as 'the way in which technology or technological artefacts are adopted, shaped and then used by young people' (Carroll et al., 2002, p. 1777). This model is developed from extensive data collection and observation of young people's use of mobiles in which they discuss factors that influence young people's adoption, use and shaping of mobile technologies. These factors come into play at various stages of the appropriation model - and result in either appropriation, non-appropriation or disappropriation. The first stage of appropriation is where users decide whether or not to explore and try out the technology and are influenced in this by constraints and attractors, which include, for example, convenience and fashion. If the technology satisfies these constraints (i.e. the attractors are stronger than the constraints), the process of appropriation begins. The next stage involves assessing whether and how the technology adds value to the young people's lifestyles. Carroll et al.'s (2002) data show how in this second stage their participants view their mobile phones and the activities that they support (e.g. text messaging) as an essential component of their lives. Finally, at the third stage, there are higher-order reinforcers (e.g. reinforcement through social use in groups). We should note, however, that although it has three stages, Carroll et al. emphasise that it is not a linear model-it is more cyclical and recursive.

A number of the features that we proposed as motivating, as described earlier, map well onto this model (see Table 1). Carroll's model includes control as a general attractor in stage one of their appropriation model; we discuss it in terms of control in a learning context - where the learner is motivated because they own the goals of their learning. Four other factors fit well with the next stage of appropriation. Carroll's participants emphasised the importance of the personal nature of the device: 'it's more personal because it is you being called not your home', which maps to our 
Table 1. How appropriation features relate to motivational features

\begin{tabular}{ll}
\hline Appropriation features (Carroll et al., 2002) & Motivational features (Jones et al., 2006) \\
\hline Stage 1 attractors & \\
Cheap & \\
Convenient & Control (over goals) \\
Control & \\
Usable & \\
Familiar & \\
Fashionable & \\
Our stuff & \\
Stage 2 & Ownership (personal nature), communication \\
Social management-personal & Fun \\
Leisure use & \\
Safety/security & Continuity between contexts \\
Information management & Communication \\
Lifestyle organiser & \\
Critical mass &
\end{tabular}

category of ownership. Communication was also particularly important to the social goals of these young people in appropriating the devices: 'A mobile phone builds friendships because you can talk to them more' and another described them as 'a prerequisite for a social life'. As predicted, young people talked about using their mobiles for leisure, which maps to our category of fun. Continuity between contexts maps on to information management as this allows information such as addresses, where young people are to meet, their contacts, and so on, to be accessed while on the move. So despite the fact that the two models were derived from different contexts (a study of young people's use of mobile phones compared with a review of the literature on learning with mobile devices), there is a good mapping between these two lists of the attractive features of technologies. The one feature that does not occur in Carroll et al.'s model is learning in context, which is not surprising since Carroll et al.'s work is not focused on learning as such but on the use of mobile devices more generally.

The model of technology appropriation in Carroll et al.'s framework relates to participants' everyday use and describes stages in the technology appropriation process. It does not, however, examine the socio-cultural factors that may affect how new technologies are appropriated by individual users, including the context into which a new technology is introduced. Waycott's study of appropriation (Waycott, 2004, 2005) focused on the use of handheld devices-PDAs-as workplace and learning tools. Her ASTAM framework focuses more specifically on the sociocultural factors that influence appropriation through an activity theory analysis that also considers how new technologies fit with current technical systems. Her work also emphasises the two-way process of technology appropriation and technology mediation: in addition to appropriation, where the adoption and adaptation of technology is shaped by social and technological systems, technology mediation also takes place, 
which is the process by which tools and technologies change the activities that they support.

Like Carroll et al.'s model, Waycott's model of how mobile technology is appropriated by learners is concerned with how technology is shaped by users and adapted to their needs, but as noted above it also emphasises the bi-directional nature of this process by describing how the technologies or artefacts in turn affect and change the users' actions and their environment. She focuses on the user's objectives and their use of technology, in particular handheld technologies, to achieve these objectives.

Waycott carried out a number of case studies of participants' use of PDAs. These included: case study a, 44 learners studying a distance education course (mostly novice PDA users who used a Palm m105 PDA over the final two months of their course); case study b, 11 participants in an academic workplace setting who took part over two years and where three different PDA devices were given to the participants depending on their use and preferences; and case study c, a study of a large international organisation that had introduced PDA's two years previously but which were not being used very much. In this third case study, 16 participants were interviewed and there was also a very small case study of use in museums and art galleries. Waycott (2004) reports on all these studies, while Waycott (2005) reports on case studies $b$ and $c$.

Drawing on these studies, Waycott analysed how participants differed in their expectation and evaluation of the device and the relationships between the design of the device and the activity it was expected to support. The PDAs gave the distance learners, in case study a, access to some of their course materials to supplement their use of other media, which included static text and the Internet. In one of the workplace settings (case study b), academics and administrators were given PDAs to support their everyday work activities; while in the study of the large international organisation (case study c), workers in the energy industry used mobile devices to access information while they were out of the office.

Waycott uses an activity system framework to analyse the process of tool appropriation as an activity in her ASTAM framework, and activity theory concepts (Waycott et al., 2005) in her analysis of the technology integration process, which focuses on how users' activities are changed and shaped by technology use. Using an activity theory approach is helpful in understanding the social factors in appropriation. For example, in her consideration of the subject in the activity system, Waycott examines some of the past experiences, personal circumstances (time and inclination-or motivation, to use the mobile devices) and personal preferences that had an effect on how participants responded to and appropriated the PDA. Each of these will be discussed briefly below. Waycott addresses motivation when considering her participants' personal circumstances.

Participants varied in the time they had available and were prepared to make available to learn how to use the PDA. For some it was not worth the effort: 'the benefits didn't outweigh the costs, either ... of getting to know how it worked in the first place or the cost of continuing to use it whilst I got the hang of it' (Waycott, 2004, p. 161). 
Differences in personal inclination-intrinsic motivation-also had an effect on the effort that participants were prepared to put in and the time to set aside. One group of participants in the study were distance learning students. When asked about their general attitudes towards new technologies, many of these students were very positive towards technology development but their enthusiasm was focused on technologies that were useful as learning tools. For example, one participant said 'I am sufficiently interested ... in ... voice recognition and other tools so I try them out ... I'm intrinsically interested in any piece of technology that allows anybody to communicate. I would even say to the point of obsession' (Waycott, 2004, p. 161).

By contrast, a participant who had never used the PDA much commented 'I don't want the annoyance of having to re-learn different ways of working ... I'm probably too lazy to learn a new medium'. He did not have the motivation necessary to learn to use the PDA and to adapt his work or study practices in order to successfully incorporate the new tool into these activities.

Participants had different working practices, and for some there was a close fit between their working practice and use of the device. For example, one participant had previously used a diary as a time and information management system, keeping printouts of appointment schedules, agendas and emails in her paper filofax folder. The PDA simplified this system for her-it fitted neatly into her way of doing things and provided a clear added advantage. By contrast, another participant (a student) commented that he had little need of access to course materials on the move as he worked in a nine-to-five job and cycled to work: he thought that if he used trains he might well have benefited.

Waycott's activity system approach has therefore enabled a more detailed focus on social factors affecting appropriation, and on how the use of the mobile devices shaped and changed particular activities as well as how participants adapted the way they used the devices themselves.

In both Carroll et al.'s and Waycott's studies, an outcome of successful adoption is increased dependence on the tool. Both the mobile phones used by the young people and the PDAs were viewed as highly personal tools: 'it goes in my handbag with all those other crucially important things like my credit card, my reading glasses, my car keys ... Those are what I need to function' (Waycott, 2004, p. 174). As described earlier, one of our motivational features is ownership, and both the Waycott and Carroll studies certainly support the idea that these devices were seen as very personal resources. In response to a query about borrowing a PDA from another student, one of Waycott's participants replied:

It would be akin to lending someone my personal diary. I ... store all birthdays ... appoint-
ments, kids functions ... also personal and household finances ... names and addresses of
everyone I know ... all my security codes ... Absolutely anything and everything I need to
know is in one place. ... I could not conceive of letting anyone else look at it let alone
borrow it. (Waycott, 2004 , p. 193)

These two approaches to appropriation have some clear differences as well as some strong similarities. The models are derived from work with different mobile 
devices - and this has an impact on appropriation. At the time that Carroll et al.'s study was conducted, mobile phones were generally not as multifunctional as PDAs and were probably not as complex to learn to use. The activities for which the devices were used differed too. The mobiles were mainly used as social, communicative and organisational devices so their owners did not need to get involved in activities such as typing-up documents-which for the PDA users had an additional overload. Waycott found that the PDA's conflicted with other technologies: participants in one of her workplaces had to decide whether to take their laptops or their PDAs when they travelled: although the PDAs were relatively small and light - by the time chargers were also taken, and mobile phones, they were a significant extra when participants were trying to travel relatively light and so were often left behind in favour of the heavier laptop that supported typing and Internet access better. However, for Carroll et al.'s young participants, mobiles would not usually have been competing with other devices or technologies. Another significant difference is that the PDA was not a stand-alone technology. Participants used it as an adjunct to their main computers. It allowed them access to digital information and so on while on the move- but needed to be synchronised with the PC for full benefit.

In both models of appropriation, being part of a community, and in particular the support of other users, is particularly important. Participants made use of knowledge elicited from the communities they were part of and were influenced by practice in these communities. In Waycott's study, community knowledge also played a part in participants' decisions not to persevere with using the PDA.

\section{Coping strategies}

Another lens that we can use to understand the relationship between motivation and the use of mobile devices is Järvelä et al.'s work on coping strategies. Järvelä et al. (2000) describe three potential types of coping strategies that students could use when faced with a technology-based task: task-oriented, ego-defensive and social dependence. Using case studies, they show how students' subjective interpretations of the task and its context are important variables that interact with features of the setting and impact on the students' behaviour.

The most productive coping strategy for learning is task-oriented coping. This is characterised by an intrinsically motivated tendency to approach, explore and master the challenging aspects of the environment. So the learners' initial (cognitive) appraisal of task cues and instructions suggests to him or her that the task is doableand there is a moderate expectation of success. This coping strategy is characterised by the learner expressing curiosity, interest and enthusiasm-and these in turn promote task-approaching behaviours. Motivational tendencies such as sense of control and mastery motivation interact with cognitive processes to promote taskcoping strategies such as exploring and planning - and the cycle is reinforcing. In less productive strategies, such as ego-defensive strategies, the learner's expectation of success is low and they may believe the task is too difficult. 


\section{Application of the two approaches: the BirdWatch study}

So how does this work in practice? Next we describe how we applied these two approaches to one of our small case studies. Two recent studies by Clough and colleagues have investigated informal learning in the area of natural history. One small study investigated the use of wireless-enabled tablet PCs for taking part in a UK national survey-BirdWatch. Eight participants used tablet PCs to participate in a one-hour observation of garden birds and reported back on their experience. In one strand of the study, interviews with participants included a particular focus on motivation (Jones et al., 2006).

Although the overall task of the study was defined as taking part in the BirdWatch activity - which involved recording the number of birds of particular species that they saw within the period of an hour-the tablet PC did support learners in also defining their own goals. It turned out that this was an important element for one participant in particular, for whom things did not go as expected. She planned to do the activity with her family (including six-year-old twins) but was unable to get the wireless connection set up for the tablet PC and thus could not complete the activity in the way that she had anticipated. However, rather than abandoning the task she (and the family) subverted and appropriated it by using the tablet in conjunction with an Internet connection on another PC. Furthermore, no birds were observed, and so the task of observing birds was not possible to carry out-again the activity was changed and this led to unexpected but interesting outcomes:

\footnotetext{
We finally all got lined up along the window and there were NO birds ... there is a limit to how long they (the 6 year olds) will stare at an empty garden - they were much more interested in the technology because they had been doing a lot of work on it at school. [My son] was very excited that he could ... go on Google ... do some of the ICT suite work he had done at school. So the learning activity they were doing actually was spelling-because of course you can't use Google unless you can spell so they would be going how do you spell Samuel Pepys - so I am starting out of the window making some notes on my tablet saying how do you think it is spelt?
}

Therefore, the fact that the technology supported learners in defining their own goals and ways of accessing further information was crucial here-it allowed them to alter the task to something that they still got something out of (i.e. they developed new goals). The Carroll et al. model does not particularly add to our understanding of what happened in this case study because it does not focus on particular activities, whereas Waycott's model of appropriation and assimilation emphasises the bi-directional nature of appropriation and assimilation. The technology appropriation here is seen in the way that the PC is used alongside the tablet PC to provide the Internet access when there is a failure in setting up the wireless. The activity (i.e. the task) is also changed.

What about applying the coping strategies model to BirdWatch? This also adds something to our understanding of what happens here because, according to Järvelä et al. (2000), what is important is what the student's coping efforts are: these are initially influenced by the environment (social interaction, cultural conventions, etc.), 
and by the socio-emotional, motivational and cognitive interpretations made by the learner; and in turn these are influenced by their emotionally important experiences from their learning histories - and the quality of learning strategies available for them in that particular domain. So, applying this to the BirdWatch case study, and in particular to this family, it can be argued that this participant took a task-oriented coping strategy characterised by 'an intrinsically motivated tendency to approach, explore and master the challenging aspects of the environment'. In such an approach, the learners' appraisal of the task and instructions leads her to think that the task is one that she can do and there is a moderate expectation of success. Järvelä et al.'s examples of task-oriented coping behaviours include exploring and planning. In this case, of course, it turns out that the task as set is not do-able-there are no birds - and neither is she able to get the wireless set-up to work. However, the approach taken is very consistent with a model in which emotions such as interest, curiosity and enthusiasm are evident - and in the absence of being able to carry out the original task allow the learner to change the task and goals to those that are achievable. It would also suggest that other individuals in the same situation who were less task-oriented and less confident of being successful might easily give up or invoke other less productive coping strategies. For example, ego-defensive coping is dominated by self-defence and self-protective motives-the learner does not view himself or herself as an active agent but more passively, so not strongly in control. They become sensitised to task difficulty cues and demand aspects-and initial appraisal may lead to interpretations such as 'it is too difficult', and expectations of success are low. We can see how in this situation such a strategy would have been reinforced by the difficulty of the task.

\section{Conclusion}

In this paper, we have discussed two theoretical approaches-appropriation and coping strategies - and considered these in terms of how they relate to what motivates learners to use mobile devices. We then provided an illustration of their application by applying them to a case study from our own research on motivation and mobile technologies. We found that one approach, the coping strategies, enabled us to further our understanding of the use of mobile technologies, while the other approach, appropriation, was also helpful but in a different sense. Appropriation as defined by Carroll et al. was not so helpful in this context, but Waycott's model was helpful in thinking about the bi-directional relationship between appropriation and assimilation, and in particular the way in which the mobile technology was used with another tool-the fixed PC.

The two different theoretical approaches work at different levels of granularitythe Järvelä et al. theoretical approach is based on relatively small episodes of learning and is helpful in the BirdWatch case study. One way of interpreting this example is that it extends Järvelä et al.'s model because, as it is informal learning, with a task that is not a requirement for a formal course, the task-oriented coping strategy that was used is in fact an 'other task-oriented strategy' (i.e. the participants changed the task 
to one that was relevant to them and that they were able to do in the given context with the mobile device available to them). This was facilitated by the nature of the tool, which is very flexible. In contrast, the appropriation models work at a different level, over a much longer period of time.

It therefore appears that the coping strategy model is useful in terms of explaining small incidences of learning, while the appropriation model as defined by Waycott is more useful for understanding the larger contextual aspects of the use of mobile technologies, and their relationship to other technologies in the setting.

\section{References}

Carroll, J., Howard, S., Vetere, F., Peck, J. \& Murphy, J. (2002) Just what do the youth of today want? Technology appropriation by young people, in: R. H. Sprague (Ed.) Proceedings of the 35th Hawaii International Conference on System Sciences (HICSS-35), Maui, HI, January, 1777-1785. Available online at: http://ieeexplore.ieee.org/xpls/abs_all.jsp?arnumber $=994089$ (accessed 22 October 2007).

Clough, G., Jones, A., McAndrew, P. \& Scanlon, E. (In press) Informal Learning with PDAs and Smartphones, fournal of Computer Assisted Learning.

Corlett, D., Sharples, M., Bull, S. \& Chan, T. (2006) Evaluation of a mobile learning organizer for university students, Fournal of Computer Assisted Learning, 21(3), 162-170.

Crook, C. K. (2000) Motivation and the ecology of collaborative learning, in: R. Joiner, K. Littleton, D. Faulkner \& D. Miell (Eds) Rethinking collaborative learning (London, Free Association Press), 161-178.

Issroff, K., Scanlon, E. \& Jones, A. (2007) Affect and mobile technologies: case studies, paper presented at the Beyond Mobile Learning Workshop, Kaleidoscope Network of Excellence, Switzerland, January. Available online at: http://mlearning.noe-kaleidoscope.org/repository/ Beyond\% 20Mobile\%20Learning\%20Book\%20Proceedings\%2011.1.07.pdf (accessed 31 August 2007).

Järvelä, S., Lehtinen, E. \& Salonen, P. (2000) Socioemotional orientation as a mediating variable in teaching learning interaction: implications for instructional design, Scandinavian fournal of Educational Research, 44(3), 293-306.

Jones, A. C. \& O'Shea, T. (1982) Barriers to the use of computer assisted learning, British fournal of Education and Technology, 13(3), 207-217.

Jones, A., Issroff., K, Scanlon, E., Clough, G. \& McAndrew, P. (2006) Using mobile devices for learning in informal settings: is it motivating?, paper presented at the IADIS International Conference on Mobile Learning, Dublin, 14-16 July.

Kirkwood, A. \& Price, L. (2005) Learners and learning in the twenty-first century: what do we know about students' attitudes towards and experiences of information and communication technologies that will help us design courses?, Studies in Higher Education, 30(3), 257-274.

Kukulsak-Hulme, A. (2007) Mobile usability in educational contexts: what have we learnt?, The International Review of Research in Open and Distance Learning, 8(2). Available online at: http:// www.irrodl.org/index.php/irrodl/article/view/356/879 (accessed 31 August 2007).

Livingstone, D. (2006) Informal learning, in: Z. Bekerman, N. C. Burbules \& D. S. Keller (Eds) Learning in places: the informal education reader (New York, Peter Lang Publishers), 203-227.

Pettit, J. \& Kukulska-Hulme, A. (2007) Going with the grain: mobile devices in practice, Australasian fournal of Educational Technology, 23(1), 17-33. Available online at: http:// www.ascilite.org.au/ajet/ajet23/pettit.html (accessed 31 August 2007).

Sharples, M., Taylor, J. \& Vovoula, G. (2007) A theory of Learning for the Mobile Age, in: R. Andrews, \& C. Haythornthwaite (Eds) The Sage Handbook of E-learning Research (London, Sage), 221-247. 
Smørdal, O. \& Gregory, J. (2003) Personal digital assistants in medical education and practice, fournal of Computer Assisted Learning, 19, 320-329.

Tough, A. (1979) The adult's learning projects (Ontario, Ontario Institute for Studies in Education).

Twining, P. \& Evans, D. (2005) Should there be a future for Tablet PCs in schools?, fournal of Interactive Media in Education. Available online at: http://www-jime.open.ac.uk (accessed 31 October 2007.

Vavoula, G. \& Sharples, M. (2002) Requirements for the design of lifelong learning organisers, in: Proceedings of MLEARN2002, European Workshop on Mobile and Contextual Learning, Birmingham, pp. 23-26. Preprint available online at: http://www.lsri.nottingham.ac.uk/msh/ Papers/vavoula\%20sharples\%20MLearn\%202002.pdf (accessed 31 August 2007).

Waycott, J. (2004) The appropriation of PDAs as learning and workplace tools: an activity theory perspective. Ph.D. thesis, Open University, Milton Keynes. Available online at: http:// kn.open.ac.uk/public/workspace.cfm?wpid=5411 (accessed 31 August 2007).

Waycott, J. (2005) Appropriating tools and shaping activities: the use of PDAs in the workplace, in: A. Lasen \& L. Hamill (Eds) Mobile World: Past, Present and Future (Springer-Verlag London Ltd.).

Waycott, J., Jones, A. \& Scanlon, E. (2005) An activity theory framework for analyzing PDAs as lifelong learning tools, Learning Media and Technologies, 30(2), 107-130. 